\title{
University Students' Attitudes toward the Formal Integration of Facebook in their Education: Investigation Guided by Rogers' Attributes of Innovation
}

\author{
Reham Mohammad Almohtadi ${ }^{1, *} \&$ Intisar Turki Aldarabah ${ }^{1}$ \\ ${ }^{1}$ Department of Curriculum and Instruction, College of Education, Al-Hussein Bin Talal University, Jordan \\ *Correspondence: Department of Curriculum and Instruction, College of Education, Al-Hussein Bin Talal University, \\ Jordan. E-mail: Dr.almohtadi@ahu.edu.jo \\ Note: This research was funded by the Deanship of Scientific Research and Graduate Studies at Al-Hussein Bin Talal \\ Universit
}

Received: June 8, 2020

Accepted: July 27, $2020 \quad$ Online Published: February 10, 2021

doi:10.5430/wje.v11n1p20

URL: https://doi.org/10.5430/wje.v11n1p20

\begin{abstract}
The aim of the study was to examine students' attitudes toward the formal integration of Facebook in their education at Al- Hussein Bin Talal University and to examine the relationship between their attitudes and their perceptions of Facebook's attributes. The investigation was guided by Rogers' (2003) attributes of innovation. A descriptive method was adopted in which a questionnaire was used to collect data from 99 undergraduate university students from the college of education. The results show that the students have positive and high attitudes toward the formal integration of Facebook in their teaching. In addition, the students have positive perceptions of Facebook in terms of its relative advantage, ease of use, compatibility, trialability, and observability. Furthermore, Regression analysis showed that $46 \%$ of the variance of the students' attitudes toward the formal integration of Facebook in their education can be accounted for by its linear relationship with the five independent variables: relative advantage, ease of use, compatibility, trialability, and observability. Based on the results, set of recommendations were provided.
\end{abstract}

Keywords: facebook, education, Jordan, attributes of innovation

\section{Introduction}

Social networking sites have become very popular among university students across the world. Social networking sites hold the attention of most of the internet audience. They are a universal communication tools and allow users to solve a wide range of tasks in the field of marketing, advertising and human resources management. The popularity of the use of social networking sites is led by the popularity of Smart phones among the university students. For instance, In Jordan, Gasaymeh (2017A) found that $98.8 \%$ of the first year university students owned at least one Smartphone. In Kuwait, Almisad and Alsalim (2018) found that $100 \%$ of the sample of undergraduate students owned Smartphone.

University students relay on these sites to accomplish personal and educational tasks. For instance, the research showed that large percentage of students used social networking sites to share music files with others, to share pictures with others, to share videos with others, to keep in touch with friends, to keep in touch with parents, to keep in touch with relatives, to chat with specific electronic groups, to keep others informed of what's going on in their life (Gasaymeh, 2017B). On the education side, Gasaymeh, (2017B) found that university students use social networking sites to communicate with their classmates about matters related to courses requirements, communicate with their instructor about matters related to courses requirements, to publish courses announcements, to discuss ideas about courses with my classmates, discuss ideas related to courses with instructors, to seek help related to the course requirements of students who have already taken the courses, to post links to topics and resources related to courses, to form student groups for educational purposes, to organize meetings with their classmates regarding the assignment and projects required by the instructors, to communicate with instructors about office hours and meetings, to build good relationships with the instructors, to get feedback from course instructors, and to organize their time to study. Roblyer et al. (2010) found that university students would accept the use of Facebook to support their official 
classroom work. Furthermore, the intensity of the use of social networking sites among university students was related to the students' social intelligence. For instance, Bsharah, Gasaymeh, \& Abdelrahman, (2014) found that significant and positive relationship between Facebook use and perceived level of social intelligence among sample Jordanian university students.

Facebook is one of the most popular social networking sites among university students. Facebook has several technical capabilities that make it suitable to be used as learning management system. Research studies have found positive effect of the use of Facebook on university students' achievement in different majors e.g., English Language (Ibrahim, 2013; Al-Abdallat, 2018; Al-Tamimi, Al-Khawaldeh, Natsheh, \& Harazneh, 2018) technology related course (O'Bannon, Beard, \& Britt, 2013). Students would be satisfied with the use of Facebook. For educational institution the use of Facebook is free and they can substitute the use of costly learning management system. Students are more involved in social networking sites than any other web resources. Many teachers are familiar with the use of learning management systems, but students tend to rarely rely on them, unless it necessary. Facebook offers students the opportunity to share what they learned, not only with their fellow students, but with world. However, there is a need to examine students' acceptance of the formal integration of Facebook in their education and the factors that would influence such acceptance. The aim of the current study was to examine students' attitudes toward the formal integration of Facebook in their education at Al- Hussein Bin Talal University and to examine the relationship between their attitudes and their perceptions of Facebook's attributes. The investigation was guided by Rogers' (2003) attributes of innovation. The following section discuss Rogers' (2003) model of diffusion and adoption of innovation and the previous studies that investigated the roles Rogers' (2003) attributes of innovation in shaping individuals' acceptance of the use of innovation and the adoption of Facebook for educational purposes.

\section{Theoretical Framework and Previous Studies}

There are several models that were developed to examine and explain the diffusion and adoption of innovation. These models help educational stakeholders in understanding the way the new idea or technology diffuse among individual and society. In addition these models help in understanding the factors that affect the adoption of new technology and the rate of adoption. Understanding the diffusion process of new technology helps stakeholders in planning and designing the programs that facilitate and accelerate the process of adoption. In the educational field, grasping the process of adoption of new technology prepares educators to work effectively with potential adopters.

One of the popular model of diffusion and adoption of innovation is proposed by Rogers (2003), who indicated that the diffusion process has four elements: the innovation, communication channels, time, and social system. Rogers (2003) defined diffusion as "the process by which an innovation is communicated through certain channels over time among the members of a social system" (p. 5). Rogers (2003) discussed the innovation-decision process, individual innovativeness, rate of adoption; attributes of the innovation, communication channels, and the diffusion network (Rogers, 2003).

Based on by Rogers (2003), when individual encounter new technology, he/she would got through the adoption decision process, where the innovation as a decision process, consists of five stages: Knowledge, persuasion, decision, implementation, and confirmation. Rogers (2003) identified five types of individaual when ot comes to the adoption of innovation, theses types include innovators, early adopters, early majority adopters, late majority adopters and laggards. These five types are often visually symbolizeed as S- and bell-shaped curves (Rogers, 2003).

Rogers (2003) indicated that the attributes of innovations includes five attributes of innovations: (1) relative advantage, (2) compatibility, (3) complexity, (4) trialability, and (5) observability. Rogers (2003) defined theses five attributes as the following:

Relative advantage is "the degree to which an innovation is perceived as being better than the idea it supersedes" (p. 229). "compatibility is the degree to which an innovation is perceived as consistent with the existing values, past experiences, and needs of potential adopters" (p. 15). Complexity is the "the degree to which an innovation is perceived as relatively difficult to understand and use" (p. 15). Trialability is "the degree to which an innovation may be experimented with on a limited basis" (p. 16). Observability is "the degree to which the results of an innovation are visible to others" (p. 16).

The current study employed the attributes of innovations in order to examine the university students' attitudes toward the formal integration of Facebook in their teaching. The use of attributes of innovations as the factors that determine and explain the adoption of new technology was common in many disciplines, For instance, Lin, (2011) examined the effect of innovation attributes on mobile banking adoption. For the purpose of the study 368 participants 
completed a questionnaire. The results showed that perceived relative advantage, ease of use, compatibility, competence and integrity significantly control attitude. In another study, Kebritchi, (2010) conducted a study that aimed to identify the potential factors that might affect affecting teachers' adoption of modern educational computer games. The investigation was guided by Rogers' (2003) attributes of innovations. The researcher used qualitative design in which three teachers participated in two hours interview. The results showed that compatibility, relative advantage, complexity and trialability had significant roles in the game adoption. In another similar study, Do (2008) used Rogers' five main attributes of innovation to examine the adoption rate of online learning. The researcher used a questionnaire instrument to collect data from graduate students and faculty members in a university in USA. The results showed that the Rogers' five main attributes of innovation were not successful in explaining the adoption process of the online learning. In another study related to the education field, Coleman-Prisco, (2017) conducted a study that aimed to examine factors influencing faculty innovation and adoption of open educational resources in United States higher education using Rogers' adoption model. The researcher used mixed methods design, in which 16 faculty members completed a questionnaire and 9 of them were interviewed. In relation to the participants' rating of the importance of the attributes of open educational resources that determine their adoption of these technologies, the results showed that the participants responded most favorably to the compatibility followed by relative advantage.

The previous studies showed mixed results regarding the validation of the Rogers' five main attributes of innovation in explaining the adoption of the new technology among individual. Rogers' five main attributes of innovation were used to examine individuals' adoption of different technologies. The previous studies showed that the researchers used different research designs to examine the effect of Rogers' (2003) attributes of innovation on individuals' adoption of innovation.

The adoption of Facebook for personal and educational purpose was examined in several research studies. For instance, Eren, (2012) conducted a study that aimed to examine students' attitudes towards use of Facebook in language learning course. The researchers used descriptive research in which 48 university students completed questionnaire instrument and semi-structured interviews. The results showed that the students have a extremely optimistic attitude towards the use of Facebook activity as a complement to language classroom.

In another research, Mazman and Usluel, (2010) conducted a study that aimed to design and develop a structural model clearing up how Facebook's users could employ it for educational purposes. For the purpose of the study, 606 Facebook users completed a questionnaire. The results showed that the adoption of Facebook had significant positive relationship with usefulness, ease of use, social influence, facilitating conditions and community identity. In addition, usefulness was the most important factor in predicting the use of Facebook for educational purposes. In Spain, Sánchez, Cortijo, and Javed, (2014) examined the Students' perceptions of Facebook for academic purposes. For the purpose of the study, 214 undergraduate completed a questionnaire. The results showed that social influence was the most significant reason in predicting the adoption of Facebook. In another study in Spain, Escobar-Rodríguez, Carvajal-Trujillo, and Monge-Lozano, (2014) used an extended version of the Unified Theory of Acceptance and Use of Technology (UTAUT) to investigate indirect effect of set of factors on adoption of Facebook as a learning tool. For the purpose of the study 956 university students completed a questionnaire instrument. The results showed that six factors had indirect influence on students' adoption of Facebook for educational purposes, these factors were: Performance expectancy; effort expectancy; social influence; facilitating conditions; hedonic motivation; and habit. In addition, perceived advantages and perceived relevance had direct influence on students' adoption of Facebook. In India, Dhume, et al (2012) used Technology Acceptance Model (TAM) to examine the adoption of social networking amongst 145 students in business school. The researchers used cross sectional survey design. The results showed that perceived ease of use and perceived usefulness were significant in predicting students' adoption of social networking.

The investigation of the use of Facebook for educational purpose was common in different parts of the world. The previous studies showed that the adoption of Facebook for educational purposes was influenced by various factors. The current aimed to employ Rogers' attributes of innovation to examine students' attitudes toward the formal integration of Facebook in their teaching at Al- Hussein Bin Talal University.

\section{Research Design and Methods}

The study used a descriptive approach in which participants completed a questionnaire that aimed to examine their attitudes toward the formal integration of Facebook in their teaching and their perception of Rogers' (2003) attributes of Facebook 


\subsection{Participants}

The participants were 99 students from the college of education in a university in Jordan. The researches selected number of classes that were offered in the college of education based on the willingness of the faculty member to have their students participating in the study. The participants included 99 female students and 88 male students. Table 1 shows a summary of participants' demographic attributes.

Table 1. Descriptive Summary of Students Demographic Attributes

\begin{tabular}{llll}
\hline Variable & Category & Frequency & Percent \\
\hline Gender & Male & 39 & 39.4 \\
& Female & 60 & 60.6 \\
Age & $18-20$ & 49 & 49.5 \\
& $21-25$ & 30 & 30.3 \\
& $26-30$ & 7 & 7.1 \\
& $31-35$ & 2 & 2.0 \\
& $36-40$ & 3 & 3.0 \\
Academic year & Mote than 40 & 8 & 8.1 \\
& 1 & 39 & 39.4 \\
& 2 & 39 & 39.4 \\
& 3 & 36 & 36.4 \\
\hline
\end{tabular}

\subsection{Instruments}

Table 2. Examples of the Items in the Questionnaire Instrument

\begin{tabular}{l} 
Examples of the Items in the Questionnaire Instrument \\
\hline Part one: Perception of and attitudes toward Facebook \\
First Scale: Perceptions of relative advantage of Facebook \\
- Facebook will enable me to accomplish my educational tasks more quickly. \\
- Facebook would improve the quality of my learning. \\
- Facebook would enhance my learning effectiveness. \\
Second scale: Perceptions of complexity of Facebook \\
- Learning to use Facebook is easy for me \\
- Facebook is easy to use. \\
- It will be easy for me to be skilled at using Facebook. \\
Third scale: Perceptions of compatibility of Facebook \\
- Facebook is compatible with most aspects of my learning. \\
- Facebook fits with the learning style. \\
- Facebook is well aligned with the way I love learning. \\
Fourth scale: Perceptions of trialability of Facebook \\
- The best use of Facebook in the educational process on a tentative basis in principle. \\
- I want to use Facebook correctly in my learning. \\
- I prefer to use Facebook in the educational process on a trial basis long enough to see what it can do. \\
Fifth scale: Perceptions of observability of Facebook \\
- I will use Facebook in the educational process after many other students use it. \\
- I will use Facebook in the educational process when I see others using it in their learning. \\
- I will use Facebook in the educational process after learning about its educational applications. \\
Sixth scale: Attitudes toward the formal integration of Facebook in education \\
- Using Facebook in the educational process is a good idea. \\
- Using Facebook in the educational process will be a fun experience \\
- I like the idea of using Facebook in the educational process. \\
\hline
\end{tabular}


The used instrument was a questionnaire that consisted of two parts. The first part consisted from six scales: (1) Perceived relative advantage of Facebook that had 5 items, (2) Perceived complexity of Facebook that had 4 items, (3) Perceived compatibility of Facebook that had 3 items, (4) Perceived trial ability of Facebook that had 3 items, and (5) Perceived observability of Facebook that had 5 items, (6) and Attitudes toward the formal integration of Facebook in education that had 5 items. Table 2 shows the samples of the items in each scale. The second part consists of questions to collect data regarding students' demographic characteristics that include gender, age, and academic year.

The validity and the reliability of the used instrument were checked. The validity of the used instrument was checked through presenting the used instrument on number of faculty members who review the used instrument. The reliability of the used instrument was verified through calculating Cronbach's alpha coefficients. The values of the Cronbach's alpha coefficients were high and that verified the relaibility of the used instrument. Table 3 shows the values of the Cronbach's alpha coefficients for each scale.

Table 3. Summary of Reliability Analysis

\begin{tabular}{lcc}
\hline & Scale & Cronbach's Alpha \\
\hline 1 & Attitude & .90 \\
2 & Relative advantage & .90 \\
3 & Complexity & .85 \\
4 & Comptability & .84 \\
5 & Trialability & .78 \\
6 & Observability & .81 \\
\hline
\end{tabular}

\subsection{Procedures}

The study took place in the 2019/2020 academic year. The data were collected from number of classes over one semester using a paper-based questionnaire that had two parts and six scales. The researchers randomly selected group of faculty members who was teaching courses at the college of education. Some faculty members agreed to participate in the study and allow the researchers to collect data from their students. The researchers visited the classed and explained the purpose of the study to the student and they acquired students' consent to participate in the study. The researchers explicitly communicated to the students that the participation in the study was voluntary. The researchers handed out the paper based questionnaire to the students. The students were given enough time to complete the questionnaire. After that the researchers collected the questionnaire back. The data collected by the questionnaire were analyzed.

\subsection{Data Analysis}

Descriptive analysis and regression analysis of questionnaire data were conducted. Descriptive statistics included means and standard deviations for each scale of the questionnaire, namely; (1) Perceived relative advantage of Facebook, (2) Perceived complexity of Facebook, (3) Perceived compatibility of Facebook, (4) Perceived trialability of Facebook, (5) Perceived observability of Facebook, (6) and Attitudes toward the formal integration of Facebook in education. Correlation and regression analysis were used to identify the size of relationships between the independent variables (perceived relative advantage, perceived complexity, perceived compatibility, perceived trialability, and perceived observability) and the dependent variable (Attitudes toward the formal integration of Facebook in education). The statistical analysis software SPSS 16.0 was used for the analysis. The mean scores of the scales were grouped into five descriptive levels, namely very low, low, moderate, high, and very high. Table 4 shows the levels of the mean scores on 5-point likert scale.

Table 4. The Levels of the Mean Scores on 5-point Likert Scale

\begin{tabular}{ll}
\hline Mean scores & Level \\
\hline Less than 1.5 & Very low \\
Between 1.5 and 2.5 & Low \\
Between 2.5 and 3.5 & Moderate \\
Between 3.5 and 4.5 & High \\
Between 4.5 and 5 & Very high \\
\hline
\end{tabular}




\section{Results and Discussion}

The results regarding participants' attitudes toward the formal use of Facebook for educational purposes and their perceptions of the five main attributes of Facebook suggest that the participants have positive and high attitudes toward the formal integration of Facebook in their teaching. In addition, the students have positive perceptions of Facebook in terms of its relative advantage, ease of use, compatibility, trialability, and observability. Table 5 shows the means, standard deviation, and levels of students' responses to the scales of the questionnaire.

Table 5. Descriptive Statistics of Participants' Responses to Attitude towered the Formal Use of Facebook and their Perceptions of the Five Main Attributes of Facebook

\begin{tabular}{lcccc}
\hline & Scale & Mean & Standard deviation & Level \\
\hline 1 & Attitude & 3.81 & .88 & High \\
2 & Relative advantage & 3.57 & .77 & High \\
3 & Complexity & 4.12 & .77 & High \\
4 & Comptability & 3.55 & .89 & High \\
5 & Trialability & 4.08 & .77 & High \\
6 & Observability & 3.67 & .76 & High \\
\hline
\end{tabular}

The participants' attitudes toward the formal use of Facebook for educational purposes were high and positive ( $\mathrm{M}=$ 3.81, SD = .88). Regarding students' perceptions of the five main attributes of Facebook, the participants' perceptions of the attributes Facebook were high and positive. Participants were found to have responded most positively to complexity scale, where the students believes that Facebook is very easy to use $(\mathrm{M}=4.12, \mathrm{SD}=.77)$. The students responded least positively to comptability scale $(\mathrm{M}=3.55, \mathrm{SD}=.89)$. Previous studies showed that social networking sites were popular among college students (Gasaymeh, 2017A; Almisad \& Alsalim, 2018). Such popularity would explain that findings regarding students' perceptions of Facebook's ease of use. However, the use of social networking sites might cause social and cultural problems in Arab conservative culture (Gasaymeh \& Waswas, 2019), such limitation might explain students' responses to the comptability scale.

The correlation test was conducted to assess the strength of association among the variables: students' perception of the relative advantage, complexity, comptability, trialability, observability of Facebook and their attitudes toward the formal use of Facebook for educational purpose. The results of the correlation test are presented in Table 6.

Table 6. Bivariate Correlations among Perception of the Relative Advantage, Complexity, Comptability, Trialability, Observability of Facebook and Attitudes toward the Formal use of Facebook for Educational Purpose.

\begin{tabular}{llllll}
\hline & Attitude & $\begin{array}{l}\text { Relative } \\
\text { advantage }\end{array}$ & Complexity & Comptability & Trialability \\
\hline Attitude & 1.00 & & & & \\
Relative advantage & $* .67$ & 1.00 & 1.00 & & \\
Complexity & $* .43$ & $* .55$ & $* .59$ & 1.00 & 1.00 \\
Comptability & $* .47$ & $* .72$ & $* .61$ & $* .47$ & $* .30$ \\
Trialability & $* .36$ & $* .50$ & $* .32$ & $* .35$ & \\
Observability & $* .47$ & $* .60$ & & & \\
\hline
\end{tabular}

$* \mathrm{P}<.05$

The correlation test showed that there were significant relationships among the examined variables. The results showed that students' perception of the relative advantage, complexity, comptability, trialability, observability of Facebook had significant correlation with their attitudes toward the formal use of Facebook for educational purpose. The strongest relationship were between students' perception of the relative advantage of Facebook and their attitudes toward the formal use of Facebook for educational purpose $(r=.67, p<0.05)$. The weakest relationship were between students' perception of the Trialability of Facebook and their attitudes toward the formal use of Facebook for educational purpose $(\mathrm{r}=.36, \mathrm{p}<0.05)$. Regression analysis was conducted to investigate the strength of relationships between students' perception of the relative advantage, complexity, comptability, trialability, observability of Facebook and their attitudes toward the formal use of Facebook for educational purpose (Table 7). 
Table 7. Multiple Regression on Dependent Variable (Attitude toward the formal use of Facebook for Educational Purpose)

\begin{tabular}{lccccc}
\hline & B & SE B & Beta & t & sig \\
\hline (Constant) & .68 & .45 & & 1.52 & .13 \\
Relative advantage & .69 & .15 & .60 & 4.57 & .00 \\
Complexity & .12 & .12 & .10 & .97 & .33 \\
Comptability & -.06 & .12 & -.06 & -.47 & .64 \\
Trialability & -.01 & .11 & -.01 & -.09 & .92 \\
Observability & .11 & .11 & .10 & 1.02 & .31 \\
\hline
\end{tabular}

Note. $R^{2}=.46(p<.05)$

The results of the regression analysis showed that the five predictors, students' perception of the relative advantage, complexity, comptability, trialability, observability of Facebook explained $46 \%$ of students' attitude variance $(R=.681, F(5,93)=15, p<.05)$. In order to examine the strength of the effect of each independent variable on the dependent variable, the sizes of standardized coefficients (Beta) were examined. The values of standardized coefficients indicated that there was only one predictor significantly predicted students' attitude toward the formal use of Facebook for educational purpose. This significant predicator was students' perception of the relative advantage of Facebook $(\beta=.60, p<.05)$. The value of the explained variance of students' attitude would suggest that there are other factors that contribute in predicting students' attitude toward the formal use of Facebook for educational purpose.

The findings regarding the significance of the students' perception of the relative advantage of Facebook in predicting students' attitude toward the formal use of Facebook for educational purpose aligned with findings of some previous research studies (Kebritchi, 2010; Lin, 2011; Escobar-Rodríguez, et al, 2014; Coleman-Prisco, 2017; Dhume, et al, 2012) and did not align with the findings of others (Do; 2008). In addition, the findings regarding the insignificance of the students' perception of the other attribute of Facebook in predicting students' attitude toward the formal use of Facebook for educational purpose did not align with findings of some previous research studies (Kebritchi, 2010; Lin, 2011; Coleman-Prisco, 2017).

\section{Conclusion and Recommendations}

In the current study, the college of education students had positive attitudes $(\mathrm{M}=3.81, \mathrm{SD}=.88)$ toward the formal integration of Facebook in their education at Al- Hussein Bin Talal University. Attitudes of the college of education students were correlated positively $(.36 \leq \mathrm{r} \leq .67)$ with their perception of the relative advantage, complexity, comptability, trialability, observability of Facebook. The value of the explained variance of students' attitude would suggest that there are other factors that contribute in predicting students' attitude toward the formal use of Facebook for educational purpose. The values of standardized coefficients indicated that there was only one predictor significantly predicted students' attitude toward the formal use of Facebook for educational purpose was related to students' perceptions of the relative advantages of Facebook. On the university level, the success of the integration of technology is greatly reliant on the university students and their interest in this technology. University students' attitudes toward the formal integration of Facebook in their education signify one of the initial concerns that change agents should consider in planning for introduction such technology. Enhancing students' positive attitudes toward the formal use of Facebook for educational purpose would be possible by convincing them with the relative advantage of such technology. This study has the following recommendations for theory and practice:

- In order to gain comprehensive understanding of students' attitudes toward the integration of Facebook on their formal education there is a need to examine more factors, than the one on the current study, which might shape such attitude.

- In order to enhance students' attitudes toward the formal use of Facebook for educational purpose there is a need to convince them with the relative advantage of such technology.

- Besides studies that investigate students' attitudes toward the use of Facebook, there is a need to conduct studies that investigate faculty members and administrators' perspectives of the use of Facebook in education.

- There is a need to conduct research studies with students form other colleges rather than only from the college of education. 


\section{References}

Al-Abdallat, M. F. S. (2018). The Impact of YouTube and Facebook on the Achievement of Jordan University Students in English Language Course. The Arab Journal for Quality Assurance in Higher Education, 11(34), 3-24. https://doi.org/10.20428/AJQAHE.11.34.1

Al-Tamimi, M. F., Al-Khawaldeh, A. H., Natsheh, H. I. M. A., \& Harazneh, A. A. (2018). The effect of using facebook on improving English language writing skills and vocabulary enrichment among University of Jordan sophomore students. Journal of Social Sciences (COES\&RJ-JSS), $7(3), \quad 187-214$. https://doi.org/10.25255/jss.2018.7.3.187.214

Bsharah, M., Gasaymeh, A. M., \& Abdelrahman, M. B. (2014). The Relationship between the use of Social Networking Sites (SNS) and perceived level of social intelligence among Jordanian university students. The case of Facebook. International Journal of Psychological Studies, 6(3), 1. https://doi.org/10.5539/ijps.v6n3p1

Coleman-Prisco, V. (2017). Factors influencing faculty innovation and adoption of open educational resources in United States higher education. International Journal of Education and Human Developments, 3(4), 1-12.

Dhume, S. M., Pattanshetti, M. Y., Kamble, S. S., \& Prasad, T. (2012, January). Adoption of social networking by business education students: Application of Technology Acceptance Model (TAM). In 2012 IEEE International Conference on Technology Enhanced Education (ICTEE) (pp. 1-10). IEEE. https://doi.org/10.1109/ICTEE.2012.6208609

Do, T. (2008). Rogers' Five Main Attributes of Innovation on the Adoption Rate of Online Learning. Online Submission. Retrieved from https://files.eric.ed.gov/fulltext/ED503413.pdf

Eren, Ö. (2012). Students' attitudes towards using social networking in foreign language classes: A Facebook example. International Journal of Business and Social Science, 3(20).

Escobar-Rodríguez, T., Carvajal-Trujillo, E., \& Monge-Lozano, P. (2014). Factors that influence the perceived advantages and relevance of Facebook as a learning tool: An extension of the UTAUT. Australasian Journal of Educational Technology, 30(2). https://doi.org/10.14742/ajet.585

Gasaymeh, A. M. M. (2017A). First year students' acceptance of the formal integration of smartphones into their learning: a study using an extended TAM which includes social influences and perceived enjoyment. Journal International Journal of Instructional Technology and Distance Learning, 14(7).

Gasaymeh, A. M. M. (2017B). University Students Use of WhatsApp and their Perceptions Regarding its Possible Integration into their Education. Global Journal of Computer Science and Technology.

Gasaymeh, A. M. M., \& Waswas, D. M. (2019). The use of TAM to investigate university students' acceptance of the formal use of smartphones for learning: a qualitative approach. International Journal of Technology Enhanced Learning, 11(2), 136-156. https://doi.org/10.1504/IJTEL.2019.098756

Ibrahim, M. G. (2013). The Effect of Using Facebook on Improving Students' Writing Skills in English (Doctoral dissertation).

Kebritchi, M. (2010). Factors affecting teachers' adoption of educational computer games: A case study. British Journal of Educational Technology, 41(2), 256-270. https://doi.org/10.1111/j.1467-8535.2008.00921.x

Lin, H. F. (2011). An empirical investigation of mobile banking adoption: The effect of innovation attributes and knowledge-based trust. International journal of information management, 31(3), 252-260. https://doi.org/10.1016/j.ijinfomgt.2010.07.006

Mazman, S. G., \& Usluel, Y. K. (2010). Modeling educational usage of Facebook. Computers \& Education, 55(2), 444-453. https://doi.org/10.1016/j.compedu.2010.02.008

O'Bannon, B. W., Beard, J. L., \& Britt, V. G. (2013). Using a Facebook group as an educational tool. Effects on student achievement. Computers in the Schools, 30(3), 229-247. https://doi.org/10.1080/07380569.2013.805972

Roblyer, M. D., McDaniel, M., Webb, M., Herman, J., \& Witty, J. V. (2010). Findings on Facebook in higher education: A comparison of college faculty and student uses and perceptions of social networking sites. The Internet and higher education, 13(3), 134-140. https://doi.org/10.1016/j.iheduc.2010.03.002

Rogers, E. M. (2003). Diffusions of Innovations (15th ed.). New York: Free Press.

Sánchez, R. A., Cortijo, V., \& Javed, U. (2014). Students' perceptions of Facebook for academic purposes. Computers \& Education, 70, 138-149. https://doi.org/10.1016/j.compedu.2013.08.012 


\section{Copyrights}

Copyright for this article is retained by the author(s), with first publication rights granted to the journal.

This is an open-access article distributed under the terms and conditions of the Creative Commons Attribution license (http://creativecommons.org/licenses/by/4.0/). 